\title{
Characteristics and possible mechanisms of $46, X Y$ differences in sex development caused by novel compound variants in NR5A1 and MAP3K1
}

Yiping Cheng ${ }^{1,3}$, Jing Chen ${ }^{2,7^{*}}$, Xinli Zhou ${ }^{1,3}$, Jiangfei Yang ${ }^{4}$, Yiming $\mathrm{Ji}^{1,3}$ and Chao X $\mathrm{u}^{1,3,5,6^{*}}$ (D)

\begin{abstract}
Background: Dozens of genes are involved in 46, XY differences in sex development (DSD). Notably, about 3/4 of patients cannot make a clear etiology diagnosis and single gene variant identified cannot fully explain the clinical heterogeneity of 46, XY DSD.

Materials and methods: We conducted a systematic clinical analysis of a 46, XY DSD patient, and applied wholeexome sequencing for the genetic analysis of this pedigree. The identified variants were analyzed by bioinformatic analysis and in vitro studies were performed in human embryonic kidney 293T (HEK-293T) cells which were transiently transfected with wild type or variant NR5A1 and MAP3K1 plasmid. Furthermore, protein production of SRY-box transcription factor 9 (SOX9) was analyzed in cell lysates.

Results: A novel NR5A1 variant (c.929A > C, p. His310Pro) and a rare MAP3K1 variant (c.2282T > C, p. Ile761Thr) were identified in the proband, whereas the proband's mother and sister who only carry rare MAP3K1 variant have remained phenotypically healthy to the present. These two variants were predicted to be pathogenic by bioinformatic analysis. In vitro, NR5A1 variant decreased the SOX9 production by $82.11 \%$ compared to wild type NR5A1, while MAP3K1 variant had little effect on the SOX9 production compared to wild type MAP3K1. Compared to wild type NR5A1 transfection, the SOX9 production of cells transfected with both wild type plasmids decreased by about $17.40 \%$. Compared to variant NR5A1 transfection, the SOX9 production of cells transfected with both variant plasmids increased by the $36.64 \%$.
\end{abstract}

Conclusions: Our findings suggested the novel compound variants of NR5A1 and MAP3K1 can alter the expression of SOX9 and ultimately lead to abnormality of sex development.

Keywords: 46, XY differences in sex development, NR5A1, MAP3K1, Diagnosis, Heterogeneity

*Correspondence: chenjing8469899@126.com; doctorxuchao@163.com ${ }^{1}$ Department of Endocrinology and Metabolism, Shandong Provincial Hospital, Cheeloo College of Medicine, Shandong University, Jinan 250021, Shandong, China

${ }^{2}$ Department of Child Health, Women and Children's Hospital, School of Medicine, Xiamen University, Xiamen, Fujian, China

Full list of author information is available at the end of the article

\section{Background}

46, XY differences in sex development (46, XY DSD; ORPHA 251510) refers to the abnormal sexual differentiation process of 46, XY males caused by different reasons, and the phenotypic sex and/or appearance of gonads are inconsistent with chromosomal sex [1]. 46, XY DSD is a significant cause of birth defects, which not only brings physical and mental harm to patients, but also burdens 
the family. Data on the incidence of 46, XY DSD are rare and estimates vary widely. Androgen insensitivity syndrome (AIS) is thought to be the most common etiology of 46, XY DSD followed by gonadal dysgenesis. The incidences of AIS and gonadal dysgenesis are reported to be $1-5$ per 100000 births and 1 per 80000 births, respectively [2]. 46, XY DSD is a group of diseases with highly heterogeneous phenotype: the abnormal external genitalia can be completely male or completely female, and more often, it is manifested as a phenotype between female and male, such as clitoral enlargement, hypospadias, labia majora fusion, and undescended testicles [3]. Therefore, clinical diagnosis is very difficult and more than $50 \%$ of cases could not be accurately diagnosed [4]. Genetic analysis can quickly and accurately detect the etiology of DSD, but with high cost and low penetration rate about $3 / 4$ of 46 , XY DSD cannot make an unambiguous etiology diagnosis [5]. NGS panels or whole-exome sequencing (WES) can explain $30 \%$ of case, that is to say, a lot are unexplained for clinicians. In addition, the genetic background of 46, XY DSD is complex, involving dozens of genes as AR, NR5A1, MAP3K1, SRD5A2, etc. [6], and single variant identified cannot fully explain the phenotype heterogeneity of $46, \mathrm{XY}$ DSD.

The NR5A1 gene (OMIM 184,757) plays a key role in human sex differentiation, sexual development and steroidogenesis [7]. It encodes steroidogenic factor 1 (SF-1) that controls multiple steps of adrenal gland and gonadal development: SF-1 in fetal testicular support cells actively regulates the expression of two genes, SRYbox transcription factor 9 (SOX9) and Anti-Müllerian hormone $(A M H)$, which are involved in sex determination and differentiation in male $[8,9]$; SF-1 in Leydig cells controls the expression of various enzymes required for steroidogenesis, such as STAR, CYP11A1 and CYP17A1, which ultimately leads to gonad masculinization $[10,11]$. The pathogenic NR5A1 variations are thought to account for $9-10 \%$ of 46 , XY DSD [12-14] and are closely related to the diverse phenotype of 46, XY DSD. Patients with NR5A1 variations have a variety of clinical manifestations ranging from a complete female appearance to varying degrees of masculinization $[13,15]$. In addition to the NR5A1 gene, DSD can also be caused by mutations in other genes, such as the MAP3K1 gene. As one of the common mutated genes in 46, XY DSD, MAP3K1 variants have been showed in $13-18 \%$ of 46 , XY DSD patients $[16,17]$. The MAP3K1 gene encodes a significant serine/threonine protein kinase (MAP3K1) which has a key role in cell proliferation, differentiation and apoptosis [18]. Both NR5A1 and MAP3K1 variants can cause 46, $\mathrm{XY} D S D$, giving rise to the question of whether there is a correlation between the two molecules, which has yet to be addressed thus far.
Interestingly, we detected novel compound variants of NR5A1 and MAP3K1 in a Chinese patient with 46, XY DSD. Bioinformatics analysis shows that both variants are pathogenic, and in vitro experiments found the two variants can alter the expression of SOX9. Our research further confirms that the oligogenicity inheritance is an important mechanism of 46, XY DSD, and provides a reference for future research which can improve the genetic diagnosis rate of this disease.

\section{Methods \\ Ethical approval}

The Ethics Committee of Shandong Provincial Hospital affiliated to Shandong University approved this study which was conducted with the principles in the Declaration of Helsinki. And the consent obtained from all subjects included in the study and the children's parents was both informed and written.

\section{Subjects}

The 46, XY DSD patient with hypospadias discovered was 3 months of age in November 2018. We collected his clinical data and peripheral blood samples were drawn from the 46, XY DSD patient and this pedigree.

\section{Follow-up studies}

We have followed this pedigree for 1 year and closely tracked following information of the patient: gonadal development, intellectual development, drug treatment, gender anxiety disorder, psychological and cognitive impairment, and the developments of gonadal tumors.

\section{Whole-exome sequencing and Sanger sequencing}

Using the QIAamp DNA Mini Kit (Qiagen, Germany), genomic DNA was isolated from peripheral blood leukocytes following the manufacturer's instructions. WES was performed on genomic DNA. The exons were captured by using the SeqCap EZ Med Exome Enrichment Kit (Roche NimbleGen, USA) after DNA fragmentation, paired-end adaptor ligation, amplification and purification. By postcapture amplification and purification the DNA library was generated. The DNA library was sequenced on the Illumina HiSeq sequencing platform. Sequence data alignment to the human genome reference (hg19) and variant-calling were performed with NextGene V2.3.4 software to collecte the coverage and mean read depth of the target areas. The average coverage of the exome was $>100 \times$ and the examination of the target area had enough depth to exactly match $>99 \%$ of the target exome. Variants with low coverage were filtered out to ensure the accuracy of data analysis.

Additionally, the frequency in normal populations (Genome Aggregation Database (GnomAD)) and data 
from the Clinvar and Online Mendelian Inheritance in Man (OMIM) databases and Human Gene Mutation Database (HGMD) were performed by using our inhouse scripts and NextGene V2.3.4. We used the Standards and Guidelines for the Interpretation of Sequence Variants which was published by American College of Medical Genetics and Genomics (ACMG) and the Human Genome Variation Society (HGVS) nomenclature to determine the pathogenic variants.

Pathogenic, suspected pathogenic, or clinically ambiguous variants were detected by WES. When the suspected pathogenic or pathogenic variant was detected, we verified it by Sanger sequencing which ensured that the coverage of coding sequence can reached $100 \%$. Tagged sequencing primers of NR5A1 and MAP3K1 were designed by using Primer3 version 1.1.4 (http://www. sourceforge.net) and GeneDistiller 2014 (http://www. genedistiller.org/). Forward primer (NR5A1): 5'-TAG TTGGGTCTCAGTGGGAGGAG- $3^{\prime}$; Reverse primer (NR5A1): 5'-TCACAGAGGGTTTGGGCCAGTG-3'; Forward primer (MAP3K1): 5'-TCCTGAGCAGCCTTG TCTAATCT-3'; Reverse primer (MAP3K1): 5'-ATG TGTCATTCTTGAGGAGGGTG- $3^{\prime}$. Polymerase chain reaction (PCR) was performed in a $50 \mu \mathrm{L}$ system: $5 \mu \mathrm{L}$ $10 \times$ PCR buffer, $4 \mu \mathrm{L}$ dNTPs, $4 \mu \mathrm{L}$ genomic DNA, $1 \mu \mathrm{l}$ forward and reverse primers and $0.3 \mu \mathrm{L}$ Taq Hot Start (Takara Bio, Ohtsu, Japan). The PCR conditions contained a denaturation step $\left(94{ }^{\circ} \mathrm{C}\right.$ for $\left.5 \mathrm{~min}\right)$, followed by 40 cycles of denaturation $\left(94^{\circ} \mathrm{C}\right.$ for $\left.30 \mathrm{~s}\right)$, annealing $\left(65^{\circ} \mathrm{C}\right.$ for $30 \mathrm{~s})$ and elongation $\left(72^{\circ} \mathrm{C}\right.$ for $\left.30 \mathrm{~s}\right)$. An ABI 3730 system (Applied Biosystems, Foster City, Calif., USA) was used to sequence the amplicons, and sequence analysis was finished by visual inspection and the auto assembler software Chromas 2.6.6 (Technelysium Pty Ltd. Available at www.technelysium.com.au/chromas.html).

\section{Bioinformatic analysis}

The conservation of amino acids at mutated positions was confirmed by Clustal W (UCD, Dublin, Ireland) software. We used online software Mutation Taster (http:// www.mutationtaster.org/) to predict the potential pathogenic effects of the identified variants. The model of wild type and variant proteins was constructed with I-TASSER software (https://zhanglab.ccmb.med.umich. edu/I-TASSER/).

Site-direct mutagenesis, cloning and transient transfection By GeneArt Gene Synthesis (Thermo Fisher Scientific, Rockford, IL), wild type NR5A1 or MAP3K1 cDNA were synthesized and cloned into pcDNA3.1 vector. NR5A1 variants (pcDNA3.1-NR5A1-MU) and MAP3K1 variants (pcDNA3.1-MAP3K1-MU) were obtained by sitedirected mutagenesis. To obtain the NR5A1 His310Pro amino acidic substitution (from adenine to cytosine at nucleotide 929), we used the following primers: primer forward ACGGGCCCTCTAGACTCGAGCGCCACC ATGGACTATTCGTACGACGAG, primer reverse AGT CACTTAAGCTTGGTACCGAAGTCTGCTTGGCTT GCAGCATTTC. To obtain the MAP3K1 Ile761Thr amino acidic substitution (from thymine to cytosine at nucleotide 2282) the corresponding primers were used: primer forward ACGGGCCCTCTAGACTCGAGCGCC ACCATGGCG GCGGCG GCGGGGAATCGCGCC, primer reverse AGTCACTTAAGCTTGGTACCGACC ATGTAGTACGAAAGACTGGATGCTTC. A detailed protocol used for site-directed mutagenesis can be available upon request. All the used primers were purchased from GenScript (Cayman Islands, UK). The presence and the fidelity of pcDNA3.1-NR5A1-MU and pcDNA3.1MAP3K1-MU were confirmed by the ABI 3730 sequencing system (Applied Biosystems, Foster City, Calif., USA).

Then, the human embryonic kidney 293T/17 (HEK293T/17) cells, obtained from the National Collection of Authenticated Cell Cultures, were cultured in the high glucose Dulbecco's Modified Eagle's Medium containing 10\% Fetal Bovine Serum, 5\% penicillin-streptomycin and $2 \mathrm{mM}$ L-glutamine. Using Lipofectamine 3000 transfection reagent (Thermo Fisher Scientific), HEK293T/17 cells were transiently transfected with plasmids containing the wild type NR5A1 (pcDNA3.1NR5A1-WT) and MAP3K1 (pcDNA3.1-MAP3K1-WT) or pcDNA3.1-NR5A1-MU and pcDNA3.1-MAP3K1MU. As previously described [19], the transfection concentration of a single plasmid was $2.5 \mathrm{ug} / \mathrm{mL}$ and the concentration of each plasmid is $1.5 \mathrm{ug} / \mathrm{mL}$ at the cotransfection of the two plasmids.

After $48 \mathrm{~h}$, cells were lysed by mammalian protein extraction reagent (ThermoFisher Scientific) containing protease inhibitor cocktail (Sigma Aldrich). The HEK293T/17 cells lysates were used to analyze the protein expression of SOX 9 by Western blot.

\section{Immunoblotting}

The cells lysates mixed with Laemmli buffer containing 2-mercaptoethanol were boiled for $5 \mathrm{~min}$ at $99^{\circ} \mathrm{C}$. Proteins were separated by sodium dodecyl sulfate polyacrylamide gel electrophoresis (SDS-PAGE; $200 \mathrm{~V}$, $45 \mathrm{~min}$ ) and then transferred onto a nitrocellulose membrane (400 mA, $1 \mathrm{~h})$. Membranes were incubated overnight with primary antibodies and washed 3 times for 10 min with $0.2 \%$ tris-buffered saline Tween. Then, membranes had been incubated with secondary antibodies for $1 \mathrm{~h}$ and washed 3 times for $10 \mathrm{~min}$ with $0.2 \%$ tris-buffered saline Tween. Next, 5-min incubation between chemiluminescent HRP substrate (Millipore Corporation, Billerica, USA) and membranes were conducted and bands 
were visualized by Chemidoc XRS System (Bio-Rad, Hercules, CA). The following antibodies were used: rabbit anti-SOX9 (Abcam) and mouse anti-Actin (Servicebio).

\section{Results}

\section{Clinical manifestation}

The proband was admitted to our hospital at 3 months of age due to the perineoscrotal hypospadias. He was the second child born to a full-term pregnancy mother. The patient's lineage is shown in Fig. 1a. Family history: The proband's parents and his sister have remained phenotypically healthy to the present and denied any history of familial genetic diseases.
The genital examination showed that the penis was short, the penis head was slightly curved to the ventral side, and the foreskin was stacked on the back side of the penis head to form a headscarf, which could be turned up to reveal part of the penis head. The ventral foreskin and foreskin ligaments were absent. The penis head is flat with a shallow concave area in front. The outer urethra is located in the perineum, and the membranous proximal urethra has no urethral sponge. The central part of the scrotum is slightly divided, and the root of the scrotum extends above the root of the penis. Both testes are accessible, and their size, shape and position are normal (Fig. 1b). Testicular ultrasound (3 months old): the left testicle can be moved up to the left groin area; the right
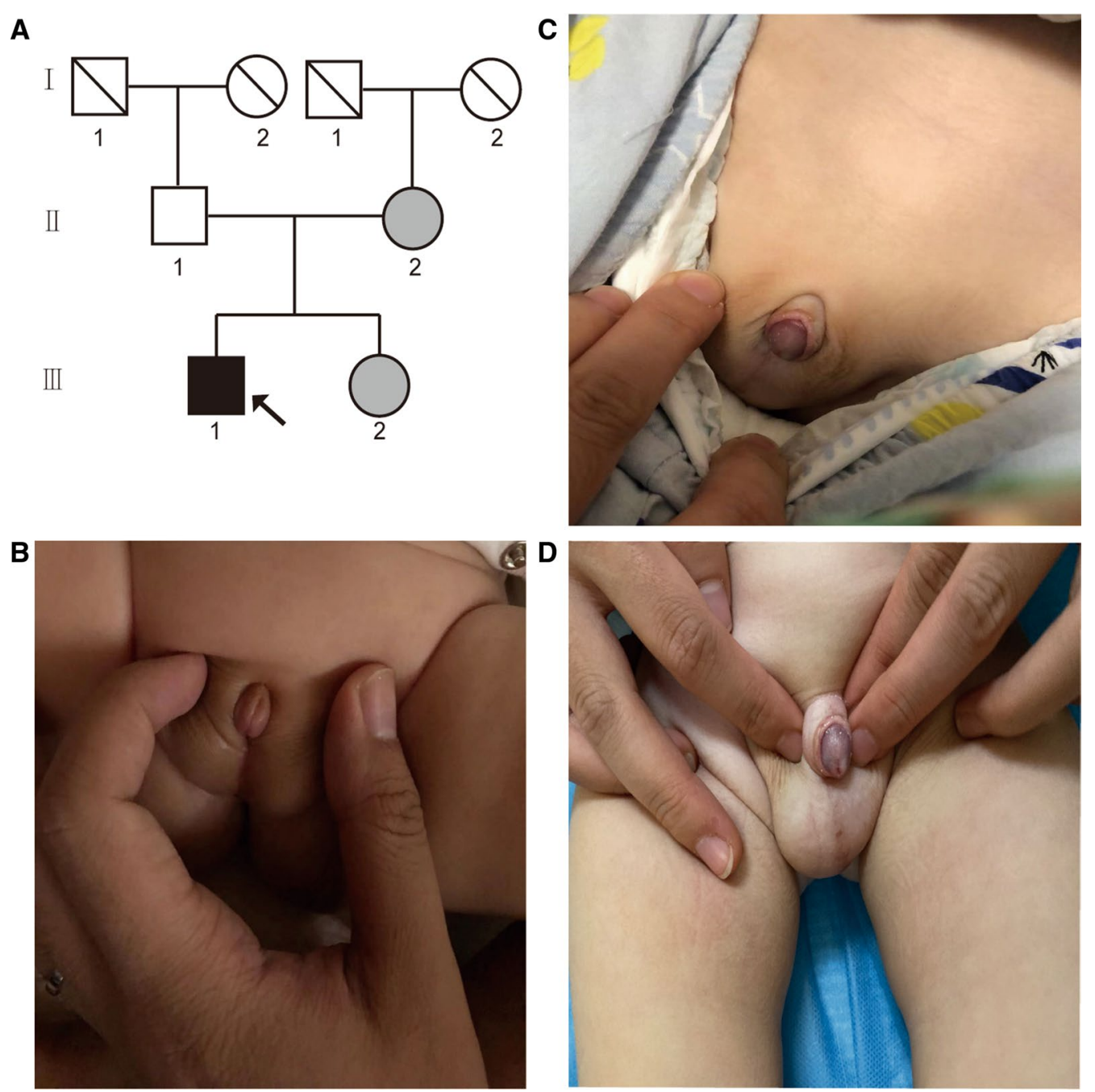

Fig. 1 The data of the patient. a The pedigree including the patient. The arrow refers to the proband. Black indicates that the person has $46, X Y$ DSD. The shading indicates that the person carries by the MAP3K1 variant but has a healthy phenotype. The slash indicates that the person has passed away. Circles indicate females reared, and squares indicate males reared. $\mathbf{b}$ External sexual organs at 3 months of age. $\mathbf{c}$ External sexual organs at 13 months of age. $\mathbf{d}$ Picture of the patient's external sexual organs at the last follow-up 
testis was located in the right scrotum; there was no echo zone at the top of the bladder.

The karyotype analysis revealed $46, \mathrm{XY}$ in 50 metaphases. Hormone measurements showed a baseline serum testosterone $(\mathrm{T})$ level of $0.1 \mathrm{ng} / \mathrm{ml}$, a post-human chorionic gonadotropin (HCG) peak level of $0.46 \mathrm{ng} / \mathrm{ml}$, 4.6 times of baseline T level; a base dihydrotestosterone (DHT) of $33.78 \mathrm{pg} / \mathrm{ml}$, and a post-HCG peak level of $79.23 \mathrm{pg} / \mathrm{ml}, 2.3$ times of baseline DHT level. This indicated that testosterone can respond to stimuli but the basal value of hormones was low, and it was necessary to continue follow-up to observe changes in hormone levels of our patient. Serum AMH was $17.7 \mathrm{ng} / \mathrm{ml}$ (Table 1). The luteinizing hormone releasing hormone (LHRH) stimulation test at 9 months showed that the patient's pituitary response was normal (Additional file 1).

\section{Follow up}

At 11 months of age, the proband underwent hypospadias repair. After the operation, the patient was referred to our pediatric endocrine clinic at 13 months of age (Fig. 1c).

The proband's last follow-up was at 1.3 years of age and the proband identified as male. Gynecological examination confirmed male external sexual organs (Fig. 1d). Testicular ultrasound (1.3 years old): The echo of testicles could be detected in both scrotums. The morphology of testicles on both sides was normal. The size of testicles on the left side was $1.7 \mathrm{~cm} \times 0.8 \mathrm{~cm} \times 0.7 \mathrm{~cm}$, and that on the right side was $1.5 \mathrm{~cm} \times 0.9 \mathrm{~cm} \times 0.6 \mathrm{~cm}$. A fluid zone is seen around the right testicle, about $0.6 \mathrm{~cm}$ deep. During the follow-up period, the proband's mental development was normal and no medication was used. In addition, potential complications, psychological or cognitive impairment, gonadal tumors or gender anxiety disorder were not observed.

\section{Mutation detection}

We subsequently applied the WES to the genetic analysis of the pedigree and found a novel heterozygous NR5A1 variant (c.929A > C) of II-1 resulting in a change in-the 310th amino acid of the encoded protein from histidine to proline (His310Pro, Fig. 2a). No substitution was detected in GnomAD, indicating that this variant is not polymorphic. As shown in Fig. $2 b$, the NR5A1 gene has one non-coding exon (exon 1) and six coding exons (exons 2-7). It encodes SF-1, consisting of 461 amino acids, which contains a DNA binding domain (DBD), a ligand binding domain (LBD), two function activation domains (AF-1 and AF-2), an auxiliary region and a hinge region. This novel variant (His310Pro) is located in the LBD and is predicted to cause a ligand-NR5A1-binding disorder and lead to NR5A1 dysfunction in sex differentiation, sexual development and steroidogenesis. MutationTaster showed that the protein properties influenced by the novel variant were pathogenic (Fig. 2c). After application of the ACMG criteria, the NR5A1 variant is "Likely Pathogenic". Multiple amino acid sequence alignments conducted by the Clustal W tool suggested that p. His310 is conserved across various species (Fig. 2d). This NR5A1 variant obviously caused changes in the $3 \mathrm{D}$ structure of the NR5A1 protein compared to wild type (Fig. 2e).

A rare heterozygous MAP3K1 variant (c.2282 T >C), which can result in a change in the 761th amino acid of the encoded protein from isoleucine to threonine (Ile761Thr, Fig. 3a), was also identified in the proband, the proband's mother and sister. The frequency of this variant in the normal person database is $\mathrm{T}=0.00007843$ (22/280512, GnomAD). The C-terminus of MAP3K1 has a conserved caspase- 3 cleavage site, a ubiquitin interaction motif (UIM) and the serine/threonine kinase domain. Two zinc finger structures, one RING structure and one SWIM region, are located at the $\mathrm{N}$-terminus of MAP3K1. The heterozygous variant occurs at position 761 (Ile761Thr) (Fig. 3b). MutationTaster showed that the protein properties influenced by the gene variant were pathogenic (Fig. 3c). Multiple amino acid sequence alignments conducted by the Clustal W tool suggested that p. Ile761 is conserved across various species (Fig. 3d). However, the structural analysis could not be performed due to the $3 \mathrm{D}$ protein of MAP3K1 cannot be crystalized currently.

Table. 1 Hormone measurements of the patient

\begin{tabular}{|c|c|c|c|c|c|c|c|c|c|c|}
\hline Months & $\mathrm{LH}(\mathrm{mIU} / \mathrm{L})$ & FSH (mIU/L) & $\mathrm{T}(\mathrm{ng} / \mathrm{ml})$ & $\mathrm{E} 2(\mathrm{pg} / \mathrm{ml})$ & $\mathrm{DHT}(\mathrm{pg} / \mathrm{ml})$ & $\mathrm{AMH}(\mathrm{ng} / \mathrm{ml})$ & $\begin{array}{l}\text { T resp. } \\
\text { hCG (ng/ } \\
\mathrm{ml} \text { ) }\end{array}$ & $\begin{array}{l}\text { DHT resp. } \\
\text { hCG (pg/ } \\
\mathrm{ml})\end{array}$ & PRL (ng/ml) & PRG $(\mathrm{mg} / \mathrm{ml})$ \\
\hline 3 & 0.5 & 4.54 & 0.1 & 20 & 20.66 & 17.7 & - & - & 8.93 & 1.26 \\
\hline 4 & - & - & 0.1 & - & 33.78 & - & 0.46 & 79.23 & - & - \\
\hline 9 & 2.31 & 12.15 & 0.93 & 20 & - & - & - & - & 13.13 & - \\
\hline
\end{tabular}




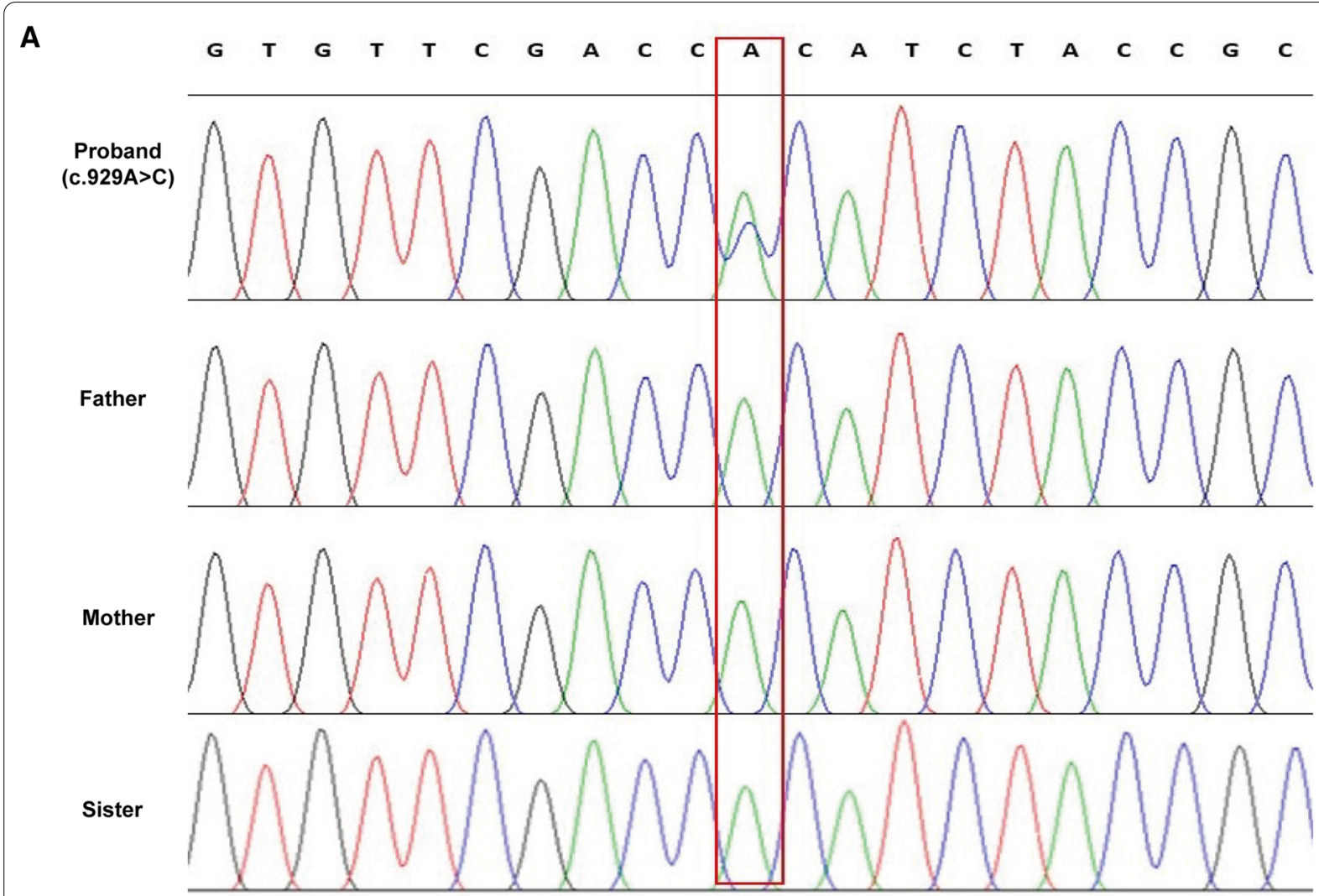

B

NR5A1 gene

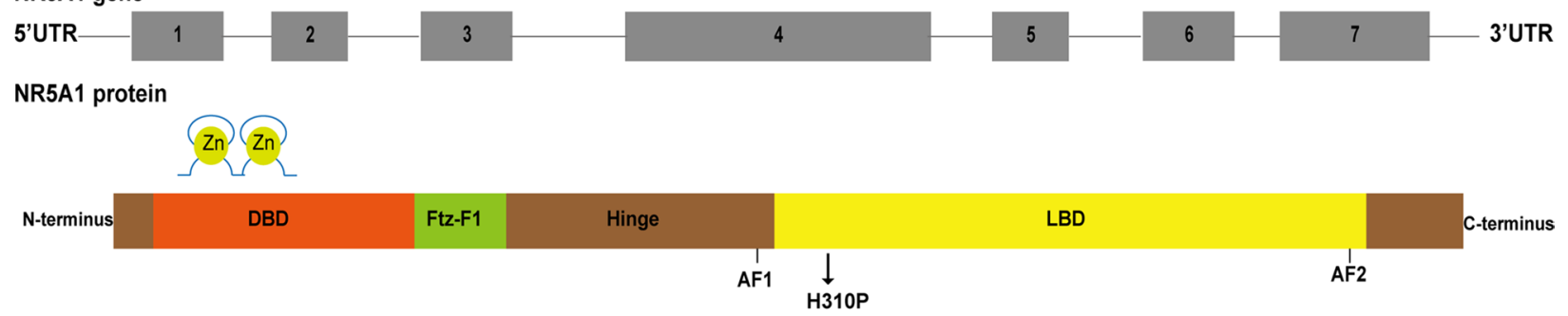

C



\section{Prediction disease causing}

Summary

- amino acid sequence changed

- protein features (might be) affected
Model: simple_aae, prob: 0.999999996009779 (explain)

hyperlink

Fig. 2 Sequencing results and bioinformatic analysis of the NR5A1 gene variant identified in our study. a Partial sequence diagram of NR5A1 in our case. A novel heterozygous variant in NR5A1 gene (c.929A > C) of II-1, resulting in the 310th amino acid of the encoded protein from histidine to proline, is shown by an arrow. $\mathbf{b}$ Location and structure NR5A1. The NR5A1 gene consists of one non-coding exon (exon 1) and six coding exons (exons 2-7). It encodes SF-1, consisting of 461 amino acids, which contains a DNA binding domain (DBD), a ligand binding domain (LBD), two function activation domains (AF-1 and AF-2), an auxiliary region and a hinge region. This novel variant (His310Pro) is located in the LBD and is predicted to cause a ligand-NR5A1-binding disorder and lead to NR5A1 dysfunction in sex differentiation, sexual development and steroidogenesis. c Prediction of the novel damaging variant c.929A >C ( $p$. His310Pro) in MutationTaster. $\mathbf{d}$ Cross-species conservation of NR5A1 around p. His310 is displayed. e Protein structure prediction of wild-type and mutant NR5A1 


\section{Species \\ Homo sapiens \\ Pan troglodytes \\ Macaca fascicularis \\ Equus caballus \\ Pongo abelii \\ Ovis aries \\ Bos taurus \\ Capra hircus \\ Monodon monoceros \\ Loxodonta africana \\ Bubalus bubalis \\ Alligator sinensis \\ Tursiops truncatus \\ Eptesicus fuscus \\ Vombatus ursinus \\ Muntiacus muntjak \\ Felis catus \\ Panthera pardus \\ Sus scrofa \\ Pteropus vampyrus}

Alignment

NCWSELLVFDHIYRQVQHGKE

NCWSELLVFDHIYRQVQHGKE

NCWSELLVFDHIYRQVQHGKE

NCWSELLVFDHIYRQVQHGKE

NCWSELLVFDHIYRQVQHGKE

NCWSELLVFDHIYRQIQHGKE

NCWSELLVFDHIYRQIQHGKE

NCWSELLVFDHIYRQIQHGKE

NCWSELLVFDHIYRQIQHGKE

NCWSELLVFDHIYRQIQHGKE

NCWSELLVFDHIYRQIQHGKE

NCWSELLVFDHIYRQVQHGKE

NCWSELLVFDHIYRQIQHGKE

NCWSELLVFDHIYRQIQHGKE

NCWSELLVFDHIYRQIQHGKE

NCWSELLVFDHIYRQIQHGKE

NCWSELLVFDHIYRQIQHGKE

NCWSELLVFDHIYRQIQHGKE

NCWSELLVFDHIYRQIQHGKE

NCWSELLVFDHIYRQIQHGKE



E
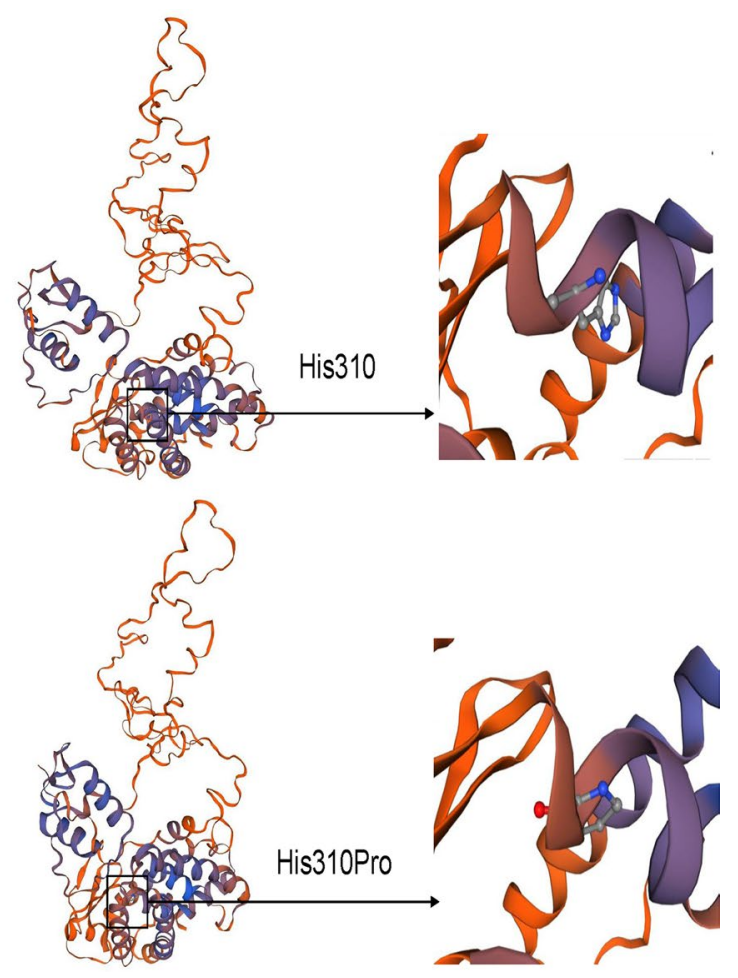

Fig. 2 continued

\section{The SOX9 protein expression in HEK293T/17 cells}

SOX9 plays an important role in testicular differentiation. We speculated that it is a common downstream signaling molecule of NR5A1 and MAP3K1. Therefore, we detected the production of SOX9 in HEK293T/17 cells subsequently. Plasmids containing the wild type NR5A1 and $M A P 3 K 1$ cDNA or carrying NR5A1 and MAP3K1 variants were transiently transfected into HEK293T/17 cells to determine the effect of the NR5A1 and MAP3K1 variants on SOX9. The SOX9 production of cells transfected with the pcDNA3.1-NR5A1-MU decreased significantly by about $82.11 \%$ compared with that of cells transfected with pcDNA3.1-NR5A1-WT. The single pcDNA3.1MAP3K1-MU transfection had little effect on the SOX9 production compared to pcDNA3.1- MAP3K1-WT. Compared to the single pcDNA3.1-NR5A1-WT transfection, the SOX9 protein production of cells transfected with both pcDNA3.1-NR5A1-WT and pcDNA3.1MAP3K1-WT decreased by about $17.40 \%$, which indicated that MAP3K1 can inhibit the expression of SOX9 and was consistent with our prediction. Compared to cells transfected with the pcDNA3.1-NR5A1-MU, the SOX9 protein production of cells transfected with both variant plasmids increased by the $36.64 \%$, which indicated that the effect of stimulating SOX9 production became strong after MAP3K1 was mutated (Fig. 4).

\section{Discussion}

In the present study, we described a 46, XY DSD patient with a novel heterozygous $N R 5 A 1$ variant (c.929A $>$ C, p. His310Pro) and a rare heterozygous $M A P 3 K 1$ variant (c.2282T >C, p. Ile761Thr). These two variants were predicted to be pathogenic by bioinformatics analysis. At the protein level, we characterized the pathogenic NR5A1 and MAP $3 K 1$ variants can affect the production of SOX9. Therefore, we hypothesize that these two identified variants are the exclusive etiology of the phenotype in our patient. Moreover, digenic inheritance may play a vital role in the phenotype spectrum of 46, XY DSD associated with NR5A1 variants.

The NR5A1 gene (OMIM 184757), located at 9q33, extends more than $30 \mathrm{~kb}$ of genomic DNA and plays a central role in human sex differentiation, sexual development, and steroid production [20-22]. 46, XY DSD with NR5A1 variants have a variety of clinical manifestations, from coplete female appearance to varying degrees of virilization. Most children present mainly with labial masses and clitoral hypertrophy that are easily misdiagnosed as AIS. Prepubertal or adolescent patients show clinical manifestations with masculinity such as micropenis, cryptorchidism, and hypospadias, which are difficult to distinguish from $5 \alpha-\mathrm{R} 2 \mathrm{D}$ [23]. In this study, our patient is a 13 months' old child with short penis and 
A

\begin{tabular}{llllllllll|l|lllllllllll}
$C$ & $T$ & $T$ & $T$ & $G$ & $T$ & $C$ & $T$ & $T$ & $A$ & $T$ & $A$ & $G$ & $A$ & $T$ & $A$ & $G$ & $A$ & $C$ & $T$ & $G$ \\
\hline
\end{tabular}

(c.2282T>C)


Mother

(c.2282T>C)

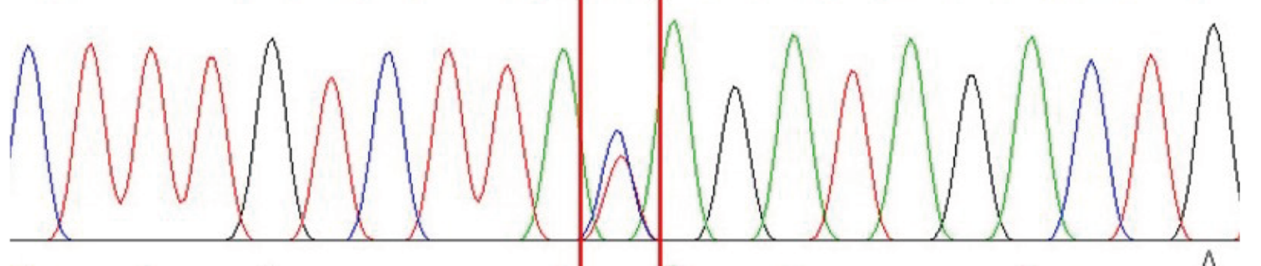

Sister

(c.2282T>C)

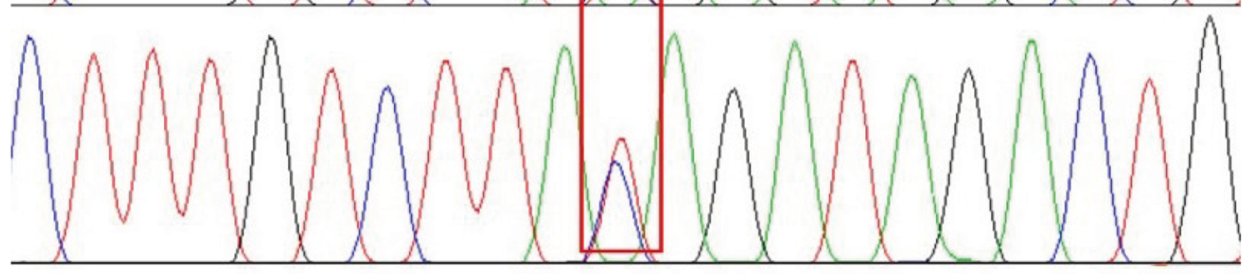

\section{B MAP3K1 gene}

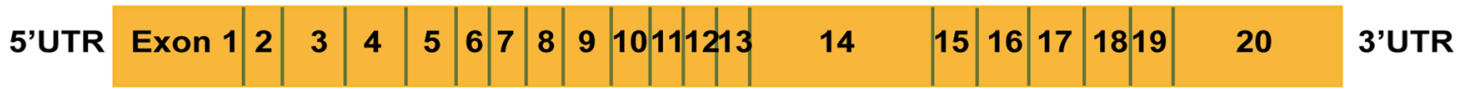

MAP3K1 protein SWIM RING Caspase Cleavage

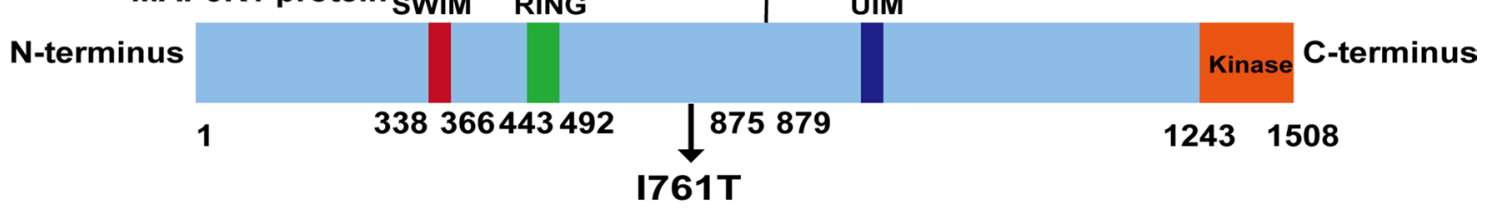

C Mutatior \$1 mutation t@sting

documentation

\section{Prediction disease causing \\ Summary

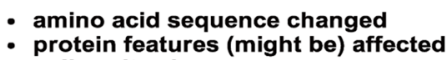

Fig. 3 Sequencing results and bioinformatic analysis of the MAP3K1 gene variant identified in our study. a Partial sequence diagram of MAP3K1 in our case. A rare heterozygous variant in MAP3K1 (c.2282T > C) of patient I-2, II-1 and II-2, resulting in the 761 th amino acid of the encoded protein from isoleucine to threonine, is shown by an arrow. $\mathbf{b}$ The structure domains of MAP3K1. Variants at the protein level are indicated below the domains. $\mathbf{c}$ Prediction of the rare damaging variant c.2282T > C (p. Ile761Thr) in MutationTaster. d Cross-species conservation of MAP3K1 around p. Ile761 is displayed 
D Species

Homo sapiens

Pan paniscus

Macaca fascicularis

Equus caballus

Pongo abelii

Ovis aries

Bos taurus

Capra hircus

Monodon monocero

Loxodonta africana

Bubalus bubalis

Muntiacus reevesi

Ailuropoda melanoleuca

Pteropus vampyrus

Castor canadensis

Physeter catodon

Camelus dromedarius

Rattus norvegicus

Erinaceus europaeus

Urocitellus parryii

Fig. 3 continued

Alignment

WQELLGRLCLIDRLLLEFPAE

WQELLGRLCLIDRLLLEFPAE

WQELLGRLCLIDRLLLEFPAE

WQELLGRLCLIDRLLLEFPAE

WQELLGRLCLIDRLLLEFPAE

WQELLGRLCLIDRLLLEFPAE

WQELLGRLCLIDRLLLEFPAE

WQELLGRLCLIDRLLLEFPAE

WQELLGRLCLIDRLLLEFPAE

WQELLGRLCLIDRLLLEFPAE

WQELLGRLCLIDRLLLEFPAE

WQELLGRLCLIDRLLLEFPAE

WQELLGRLCLIDRLLLEFPAE

WQELLGRLCLIDRLLLEFPAE

WQELLGRLCLIDRLLLEFPAE

WQELLGRLCLIDRLLLEFPAE

WQELLGRLCLIDRLLLEFPAE

WQELLGRLCLIDRLLLEFPAE

WQELLGRLCLIDRLLLEFPAE

WQELLGRLCLIDRLLLEFPAE

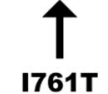

hypospadias, which are different from most children with NR5A1 variants as a labial mass and clitoral hypertrophy. We described this patient has a novel heterozygous NR5A1 variant (c.929A > C, p. His310Pro) and a rare heterozygous MAP3K1 variant (c.2282T >C, p. Ile761Thr) and suspected that the rare $M A P 3 K 1$ variant may accelerate the development of hypospadias.

The same variant in the NR5A1 gene may cause significantly different degrees of virilization in different individuals, which means that it is difficult to establish a link between genotype and phenotype. One of the possible reasons that can explain this phenomenon is the oligomeric inheritance of NR5A1 cases. Camats [15] and Mazen [24] et al. believe that there may be genetic modifiers that affect the severity of the phenotype. The $\mathrm{p}$. Arg92Trp variant is described as associated with a different phenotype. For example, $S R Y$ negative 46 , XX ovotesticular DSD and 46, XX testicular DSD [25] and SRY positive 46, XY partial gonadal dysgenesis [26].

As a part of the gene network, MAP3K1 is responsible for gonadal development and involved in the regulation of cell proliferation, differentiation and apoptosis. MAP3K1 variants can altered the binding of cofactors and increase the phosphorylation of the downstream MAP kinase pathway targets, then, the phosphorylation of ERR1/2 and p38 can be promoted and thereby 46, XY DSD occurs [27-29]. The findings of Maria et al. [30] showed that the expression of constitutively active MAP3K1 leads to the apoptosis of AR-positive cancer cells, and the reconstruction of the AR pathway makes prostate cancer cells sensitive to MAP3K1-induced apoptosis. MAP3K1 can activate the transcription factor AP-1 [31, 32], which may play a key role in the cistrome of $A R$ [33], leading to the AIS heterogeneity.

To date, only three possible cases that digenic inheritance exists in 46, XY DSD associated with NR5A1 variants have been reported. A recent study also identified pathogenic variations of NR5A1 and MAP3K1 in an individual with 46, XY DSD [24]. The patient carried a missense variant previously reported in NR5A1 (c.937C $>\mathrm{T}$, p. Arg313Cys) and a rare MAP3K1 variant (c.710A > G, p. Gln237Arg) (Table. 2). The NR5A1 variant not carried by either parent is new, while the MAP $K K 1$ variant was inherited from the mother. This patient was a 4-yearold female with ambiguous external genitalia. Genital examination found that distinct gonads were in the inguinal region and pelvic sonar confirmed the presence of both testicles in the inguinal region. A urethral opening was at the tip of the swollen clitoris. Karyotype analysis revealed 46, XY in 50 metaphases. The HCG test showed a poor testosterone response and LHRH stimulation tests revealed that the pituitary can respond to stimulation. The authors suggested that the rare $M A P 3 K 1$ variants leading to abnormal development of testes may alter the activity of MAP kinase and/or cofactor binding above threshold.

Gorjana et al. also identified two patients with two variants of testis-determining genes, the pathogenic variations of NR5A1 and ZFPM2, and the pathogenic variations of NR5A1 and SRD5A2, respectively [34] (Table 2). 




Actin

45
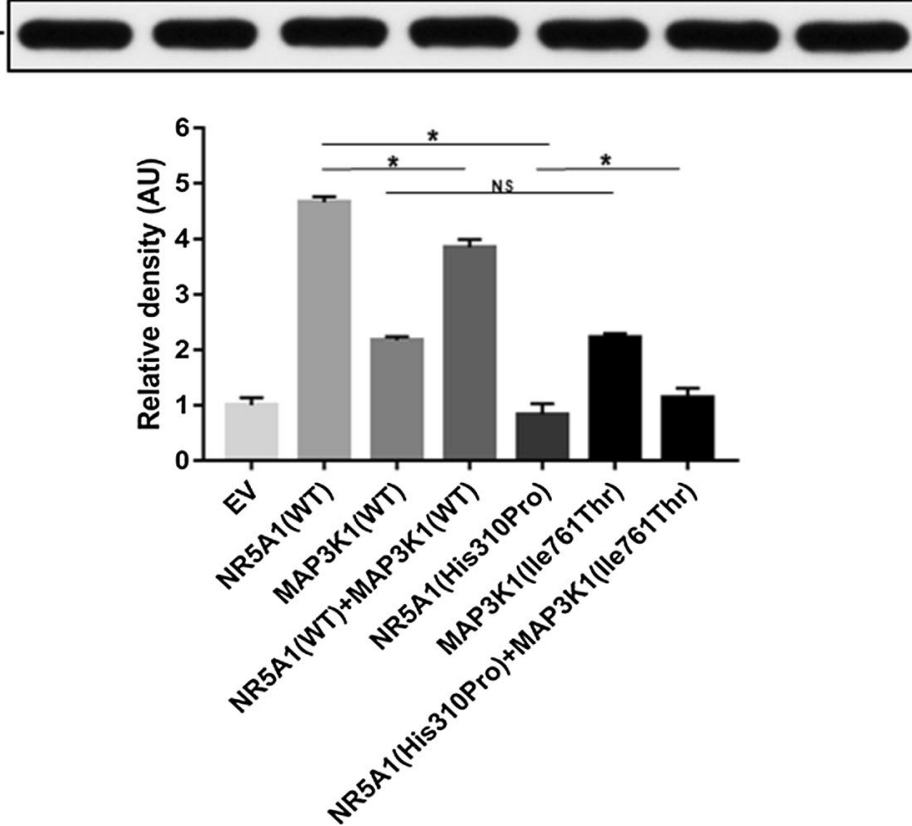

Fig. 4 Western blotting analysis of SOX9 production in HEK 293 T/17 cells. The SOX9 production of cells transfected with the PCDNA3.1-NR5A7-MU decreased significantly by about $82.11 \%$ compared with that of cells transfected with pcDNA3.1-NR5A1-WT. The single pCDNA3.1-MAP3K1-MU transfection had little effect on the SOX9 production compared to pcDNA3.1-MAP3K1-WT. Compared to the single pCDNA3.1-NR5A1-WT transfection, the SOX9 protein production of cells transfected with pCDNA3.1-NR5A1-WT and pCDNA3.1-MAP3K1-WT decreased about 17.40\%, which indicated that MAP3K1 can inhibit the expression of SOX9 and was consistent with our prediction. Compared to cells transfected with the PCDNA3.1-NR5A1-MU, the SOX9 protein production of cells transfected with both mutant plasmids increased 36.64\%, which indicated that the effect of increasing SOX9 production became strong after MAP3K1 was mutated. EV empty vector, WT wild type, NR5A1 nuclear receptor subfamily 5 group A member 1, MAP3K1 mitogen-activated protein kinase kinase kinase 1. ${ }^{*} P<0.05$, NS no statistical significance

Firstly, the study identified two patients with same NR5A1 variation (c. G251A, p. Arg84His), but they had significantly different clinical phenotypes. The testes of patient only with the variation of NR5A1 in the inguinal gonads had some function, while patient with the variations of NR5A1 (c. G251A, p. Arg84His) and ZFPM2 (c. A2107C, p. Met703Leu) had more severe clinical manifestations: no testosterone production, orchiatrophy, and in situ germ cell tumor formation. The researchers hypothesized that the accumulative effect of two different variants might be the cause of the more severe clinical phenotype of patient with double gene variants. Secondly, another patient who had NR5A1 variants (c.1114_1116del^, p. Lys372del ${ }^{\wedge}$ ) and SRD5A2 variants (c. G680A, p. Arg227Gln) presented with proximal hypospadias and bilateral scrotal gonads. The findings further highlighted the possibility that digenic inheritance may play a significant role in the phenotype heterogeneity associated with the NR5A1 variant in $46, \mathrm{XY}$ DSD. ZFPM2 protein is a polytype zinc finger cofactor, which can bind to the N-terminal zinc finger of Gata4 protein, and can act as a transcriptional co-activator or coinhibitor according to cell environment and target genes $[35,36]$. Gata4 is an evolutionarily conserved transcription factor and is essential for the early development of multiple organs including the testis. A direct interaction 
Table 2 Reported patients with digenic inheritance of 46, XY DSD associated with NR5A1 variants

\begin{tabular}{|c|c|c|c|c|}
\hline Gene & NR5A1/ZFPM2 & NR5A1/SRD5A2 & NR5A1/MAP3K1 & NR5A1/MAP3K1 \\
\hline Coding change & c.G251A/C. A2107C & c.1114_1116del^/c. G680A & c.937C $>$ T/C.710A $>$ G & c. $929 \mathrm{~A}>\mathrm{C} / \mathrm{C} .2282 \mathrm{~T}>\mathrm{C}$ \\
\hline Protein change & p. Arg84His/p. Met703Leu & p. Lys372del^/p. Arg227Gln & p. Arg313Cys/p. Gln237Arg & p. His310Pro/p. Ile761Thr \\
\hline Zygosity & Heterozygous/Heterozygous & Heterozygous/Heterozygous & Heterozygous/Heterozygous & Heterozygous/Heterozygous \\
\hline External genitalia & $\begin{array}{l}\text { Clitoromegaly one perineal } \\
\text { opening }\end{array}$ & Proximal hypospadias & $\begin{array}{l}\text { Swollen clitoris, urethral open- } \\
\text { ings at tip }\end{array}$ & hypospadias \\
\hline Gonadal location & Bilateral inguinal region & Bilateral scrotum & Bilateral inguinal region & Scrotum \\
\hline Müllerian structures & Not & Not & Not & Not \\
\hline Basal testosterone & T\&DHT markedly decreased & T-elevated, DHT-normal & T\&DHT markedly decreased & T\&DHT markedly decreased \\
\hline Basal gonadotrophins & LH-elevated, FSH-elevated & LH-normal, FSH-elevated & LH-decreased, FSH- decreased & LH-decreased, FSH-normal \\
\hline Tresp. hCG & No response & Elevated & Poor response & Elevated \\
\hline LH resp. hCG & ND & ND & Elevated & Elevated \\
\hline FSH resp. hCG & ND & ND & Elevated & Elevated \\
\hline $\mathrm{AMH}$ & Decreased & Decreased & Elevated & Elevated \\
\hline Adrenal function & Normal & Normal & Normal & Normal \\
\hline Reference & Gorjana, et al., 2017 & Gorjana, et al., 2017 & Inas, et al., 2016 & Novel \\
\hline
\end{tabular}

$A M H$ anti Müllerian hormone, $T$ testosterone, $D H T$ dihydrotestosterone, FSH follicle stimulating hormone, $L H$ luteinizing hormone, $N D$ not done, $h C G$ human chorionic gonadotropin

between Gata4 and ZFPM2 proteins may be necessary for appropriate levels of $S R Y$ expression. Anu B, et al. [37] demonstrated for the first time in humans, as in mice, that testicular dysplasia was associated with ZFPM2 variants that alter its ability to regulate expression of target genes in gonad development. Yuka et al. [38] found that the homologous proteins Six1 and Six4 play a crucial role in gonad development by regulating downstream targets ZFPM2 and NR5A1. The Six1 and Six4 genes belong to mammalian homologs of the Drosophila sine homology box (Six) family. Six1 and Six 4 are located in the same genomic region and have highly overlapping tissue expression during mouse embryogenesis [39]. Six1/Six4 transactivates NR5A1, which is connected with the initial growth of gonadal precursor cells before $S R Y$ expression begins. Second, they activate ZFPM2, which is related to the upregulation of $S R Y$ in male gonad differentiation.

The relationship between NR5A1 and MAP3K1, ZFPM2, SRD5A2 are shown in Fig. 5. Studies have shown that the homologous proteins Six 1 and Six 4 can regulate male sex determination and mouse gonad development through NR5A1 (AD4BP/SF1) and ZFPM2 (Fog2). In the regulation of male sex determination, ZFPM2 induces $S R Y$ expression, while NR5A1 determines the growth of initial gonadal precursor cells in the regulation of gonadal precursor formation. ZFPM2 interacts with activated Gata4, which may be activated by phosphorylation through the Gadd45g/MAP3K4 pathway. Activated Gata4 interacts with ZFPM2 to activate SRY and induce gonadal differentiation into testes $[38,40]$. $M A P 3 K 1$ variants can altered binding of cofactors and increase the phosphorylation of the downstream MAP kinase pathway targets-MAPK11, MAP3K and MAPK1, thereby promoting the phosphorylation of ERR1/2 and p38 and ultimately leading to the occurrence of $46, \mathrm{XY}$ DSD. Increased phosphorylation of ERK1/2 and p38 may result in decreased expression of SOX9 and increased activity of $\beta$-catenin, respectively, which are important signaling molecules in testicular and ovarian-promoting pathways [27-29]. NR5A1 and MAP3K1 can promote or inhibit the expression of SOX9 through downstream signal transduction pathways, respectively, and ultimately lead to male sex determination and differentiation.

In addition, MAP3K1 is expected to regulate the expression of $A R$ gene [19,31,33], and whether MAP3K1 and SRD5A2 (steroid 5 reductase 2, OMIM 607306) [41, 42] interact through $A R$ is worthy of further study.

To explain the underlying molecular mechanism of our genetic results, we conducted in vitro experiments of the NR5A1 and MAP3K1 variants and the accumulative effect of two different variants might be the cause of the clinical phenotype of our patient. Moreover, the pattern of inheritance of previously reported pathogenic $M A P 3 K 1$ variants is autosomal dominant and sex-limited [16, 43]. MAP3K1 variants were first described in 2010 in two large families and two of 11 sporadic cases with 46, XY DSD and an autosomal dominant, sex-limited pattern of transmission [16]. In the large family reported, phenotypic manifestations range from complete hypogonadism to hypospadias and cryptorchidism. However, 46, XX carriers were unaffected. Granados A, et al. [43] reported six individuals from four unrelated families that had 


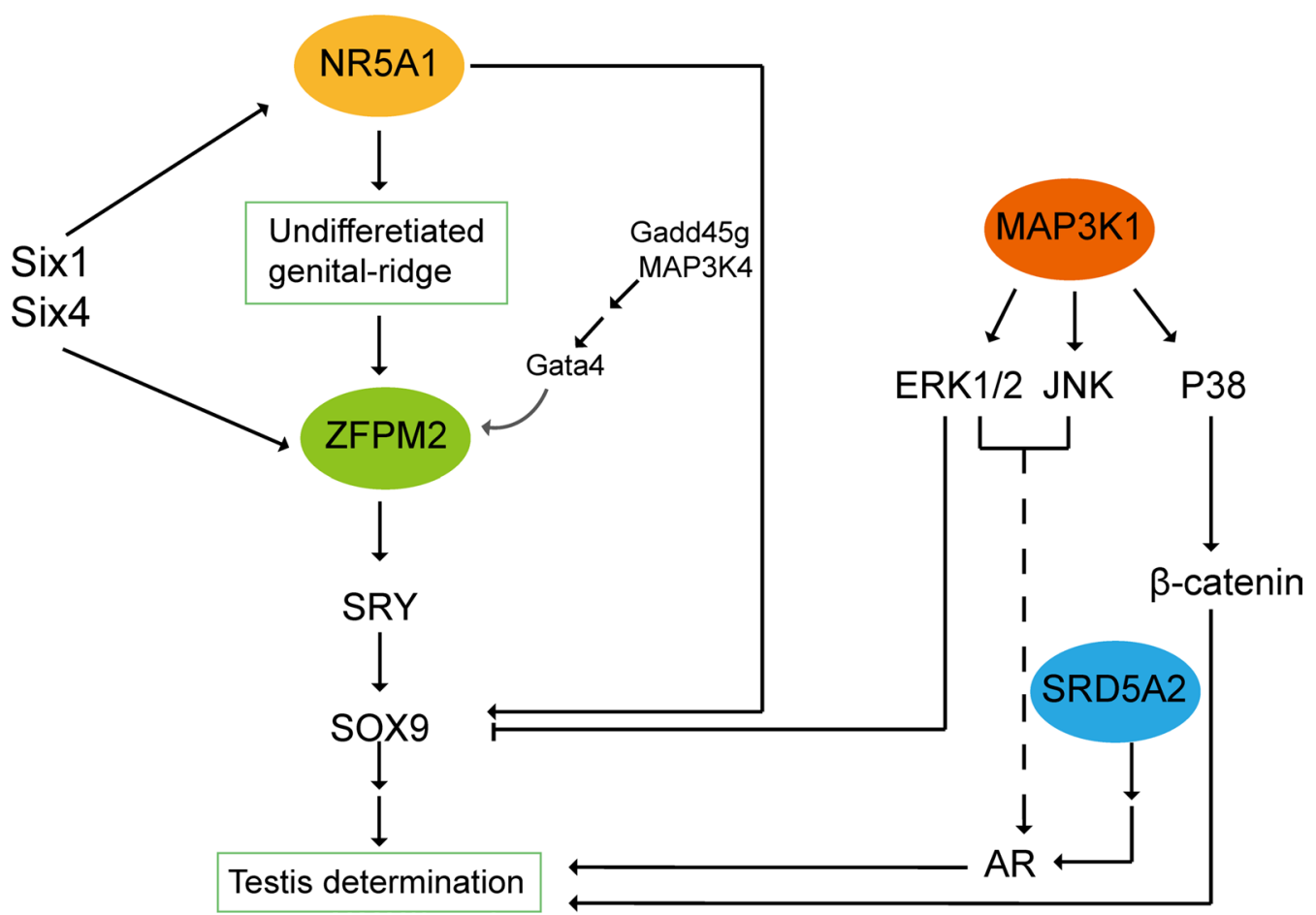

Fig. 5 Prediction of the relationship between NR5A1 and MAP3K1, ZFPM2, SRD5A2. SOX9Sry-box 9, ERK extracellular signal-regulated kinase, JNK c-Jun NH2-terminal kinase, AR androgen receptor, SRD5A2 steroid 5 reductase 2

pathogenic $M A P 3 K 1$ variants causing both partial and complete gonadal dysgenesis. Similarly, 46, XX females carrying MAP3K1 variants are unaffected. 46, XY DSD has a sex-limited autosomal dominant mode of inheritance affecting only $\mathrm{XY}$ individuals [44]. As the above studies, the mothers and sister of $46, \mathrm{XX}$ in our study have the MAP3K1 variant but remain phenotypically healthy to the present. Based on the discussion above, we have reasons to consider that this variant is pathogenic and pathogenic MAP $3 K 1$ variants has the pattern of inheritance of sex-limited autosomal dominant.

Notably, serum AMH level can reflect the health and number of Sertoli cells (SCs), the maturity of SCs and the exposure to FSH and intra-tubular testosterone [45]. The levels of serum AMH depend on the number and completeness of SCs [46]. Therefore, the reduced serum AMH level in our patient may have a special suggestive effect in the case of SCs dysfunction [47].

It is undeniable that our study has some limitations. The grandparents of our 46, XY Chinese patient had died and we cannot trace potential origin of the genetic variation. In addition, the basic experiments to validate interaction mechanism between the NR5A1 and MAP3K1 gene are temporarily lacking. Our results extend the NR5A1 and MAP3K1 variant profile. However, a lot is still unknown about the association between the phenotype and genotype of 46, XY DSD, and more 46, XY DSD patients need to be recruited for future research.

\section{Conclusions}

In summary, our study identified novel compound variants of the NR5A1 and MAP3K1 genes which can alter the expression of SOX9 and ultimately resulted in a specific phenotype of a patient with 46, XY DSD. Digenic inheritance may play a key role in the phenotypic spectrum of 46, XY DSD associated with NR5A1 variants.

\section{Abbreviations}

46, XY DSD: 46, XY differences in sex development; AIS: androgen insensitivity syndrome; SF-1: steroidogenic factor 1; SOX9: SRY-box transcription factor 9; $\mathrm{AMH}$ : anti-Müllerian hormone; ERK: extracellular signal-regulated kinase; JNK: C-Jun NH2-terminal kinase; WES: whole exome sequencing; GnomAD: genome genome aggregation database; HGMD: human gene mutation database; OMIM: online Mendelian inheritance in man; ACMG: American College of Medical Genetics and Genomics; HGVS: Human Genome Variation Society; PCR: polymerase chain reaction; T: testosterone; HCG: human chorionic gonadotropin; DHT: dihydrotestosterone; LHRH: luteinizing hormone releasing hormone; DBD: DNA binding domain; LBD: ligand binding domain; NTD: $\mathrm{N}$-terminal domain; UIM: ubiquitin interaction motif; 5a-R2D: 5a-Reductase type 2 deficiency; AR: androgen receptor; SRD5A2: steroid 5 reductase 2. 


\section{Supplementary Information}

The online version contains supplementary material available at https://doi. org/10.1186/s13023-021-01908-z.

Additional file 1 The luteinizing hormone releasing hormone (LHRH) stimulation test at 9 months. The results showed that the patient's pituitary response was normal

\section{Acknowledgements}

We kindly acknowledge the participants and researchers who participated in this study.

\section{Authors' contributions}

Y.C., C.X. and J.C. designed the study. Y.C., J.Y. Y.J. and X.Z. performed the study and analyzed the data. Y.C. wrote the main manuscript. All authors read and approved the final manuscript

\section{Funding}

This work was supported by grants from the National Natural Science Foundation (Nos. 81670720 and 81974124), special funds for Taishan Scholar Project (No. tsqn20161071), Academic promotion program of Shandong First Medical University (Grant No. 2019RC015), Shandong Key R\&D Program (Grant No. 2017GSF18129), Guiding project of the Natural Science Foundation of Fujian (2019D010), Fujian Young/Middle-aged Talent Cultivation Project (2019-ZONB31) and Xiamen Science and Technology Commission (3502Z20164029).

\section{Availability of data and materials}

All the data can be available from the corresponding author upon reasonable request.

\section{Declarations}

\section{Ethics approval and consent to participate}

\section{Applicable.}

\section{Consent for publication}

All authors have approved the manuscript and agreed with the submission and publication.

\section{Competing interests}

The authors have no multiplicity of interest to disclose.

\section{Author details}

'Department of Endocrinology and Metabolism, Shandong Provincial Hospital, Cheeloo College of Medicine, Shandong University, Jinan 250021, Shandong, China. ${ }^{2}$ Department of Child Health, Women and Children's Hospital, School of Medicine, Xiamen University, Xiamen, Fujian, China. ${ }^{3}$ Department of Endocrinology and Metabolism, Shandong Provincial Hospital Affiliated to Shandong First Medical University, Jinan, Shandong, China. ${ }^{4}$ Department of Radiology, Shandong Provincial Hospital, Cheeloo College of Medicine, Shandong University, Jinan 250021, Shandong, China. ${ }^{5}$ Institute of Endocrinology, Shandong Academy of Clinical Medicine, Jinan 250021, Shandong, China. ${ }^{6}$ Shandong Clinical Medical Center of Endocrinology and Metabolism, 324, Jing 5 Road, Jinan 250021, Shandong, China. ${ }^{7}$ Department of Child Health, Xiamen Maternal and Child Health Hospital, Xiamen, Fujian, China.

Received: 12 May 2020 Accepted: 7 June 2021

Published online: 10 June 2021

\section{References}

1. Allen L. Disorders of sexual development. Obstet Gynecol Clin N Am. 2009;36:25-45.

2. Berglund A, Johannsen TH, Stochholm K, Viuff MH, Fedder J, Main KM, Gravholt $\mathrm{CH}$. Incidence, prevalence, diagnostic delay, and clinical presentation of female 46, XY disorders of sex development. J Clin Endocrinol Metab. 2016;101:4532-40.
3. Hull CL, Fausto-Sterling A. How sexually dimorphic are we? Review and synthesis. Am J Hum Biol. 2003;15:112-5 (author reply 115-6).

4. Wertheim-Tysarowska K, Gos M, Sykut-Cegielska J, Bal J. Genetic analysis in inherited metabolic disorders-from diagnosis to treatment. Own experience, current state of knowledge and perspectives. Dev Period Med. 2015;19:413-31.

5. Rawal AY, Austin PF. Concepts and updates in the evaluation and diagnosis of common disorders of sexual development. Curr Urol Rep. 2015:16:83.

6. Eggers S, Sadedin S, van den Bergen JA, Robevska G, Ohnesorg T, Hewitt J, Lambeth L, et al. Disorders of sex development: insights from targeted gene sequencing of a large international patient cohort. Genome Biol. 2016:17:243.

7. Ferraz-de-Souza B, Lin L, Achermann JC. Steroidogenic factor-1 (SF-1, NR5A1) and human disease. Mol Cell Endocrinol. 2011;336:198-205.

8. De Santa BP, Bonneaud N, Boizet B, Desclozeaux M, Moniot B, Sudbeck P, Scherer $\mathrm{G}$, et al. Direct interaction of SRY-related protein SOX9 and steroidogenic factor 1 regulates transcription of the human anti-Mullerian hormone gene. Mol Cell Biol. 1998;18:6653-65.

9. Sekido R, Lovell-Badge R. Sex determination involves synergistic action of SRY and SF1 on a specific Sox9 enhancer. Nature. 2008;453:930-4.

10. Schimmer BP, White PC. Minireview: steroidogenic factor 1: its roles in differentiation, development, and disease. Mol Endocrinol. 2010;24:1322-37.

11. Sekido R, Lovell-Badge R. Genetic control of testis development. Sex Dev. 2013;7:21-32

12. Camats N, Pandey AV, Fernández-Cancio M, Andaluz P, Janner M, Torán N, Moreno $F$, et al. Ten novel mutations in the NR5A1 gene cause disordered sex development in 46, XY and ovarian insufficiency in 46, XX individuals. J Clin Endocrinol Metab. 2012;97:E1294-306.

13. King TF, Conway GS. Swyer syndrome. Curr Opin Endocrinol Diabetes Obes. 2014:21:504-10.

14. Adachi M, Hasegawa T, Tanaka Y, Asakura Y, Hanakawa J, Muroya K. Spontaneous virilization around puberty in NR5A1-related $46, \mathrm{XY}$ sex reversal: additional case and a literature review. Endocr J. 2018;65:1187-92.

15. Camats N, Fernandez-Cancio M, Audi L, Schaller A, Fluck CE. Broad phenotypes in heterozygous NR5A1 46, XY patients with a disorder of sex development: an oligogenic origin? Eur J Hum Genet. 2018;26:1329-38.

16. Pearlman A, Loke J, Le Caignec C, White S, Chin L, Friedman A, Warr N, et al. Mutations in MAP3K1 cause $46, \mathrm{XY}$ disorders of sex development and implicate a common signal transduction pathway in human testis determination. Am J Hum Genet. 2010;87:898-904.

17. Ostrer H. Disorders of sex development (DSDs): an update. J Clin Endocrinol Metab. 2014;99:1503-9.

18. Zheng Q, Ye J, Wu H, Yu Q, Cao J. Association between mitogen-activated protein kinase kinase kinase 1 polymorphisms and breast cancer susceptibility: a meta-analysis 20 of case-control studies. PLoS ONE. 2014;9:e90771.

19. Cheng $Y$, Sun $Y$, Ji $Y$, Jiang $D$, Teng $G$, Zhou $X$, Zhou $X$, et al. Novel compound variants of the AR and MAP3K1 genes are related to the clinical heterogeneity of androgen insensitivity syndrome. Biosci Rep. 2020:40:BSR20200616.

20. Hoivik EA, Lewis AE, Aumo L, Bakke M. Molecular aspects of steroidogenic factor 1 (SF-1). Mol Cell Endocrinol. 2010;315:27-39.

21. Parker KL, Schimmer BP. Steroidogenic factor 1: a key determinant of endocrine development and function. Endocr Rev. 1997;18:361-77.

22. Wong M, Ramayya MS, Chrousos GP, Driggers PH, Parker KL. Cloning and sequence analysis of the human gene encoding steroidogenic factor 1. J Mol Endocrinol. 1996;17:139-47.

23. Alhomaidah D, McGowan R, Ahmed SF. The current state of diagnostic genetics for conditions affecting sex development. Clin Genet. 2017;91:157-62.

24. Mazen I, Abdel-Hamid M, Mekkawy M, Bignon-Topalovic J, Boudjenah R, El Gammal M, Essawi M, et al. Identification of NR5A1 mutations and possible digenic inheritance in 46. XY Gonadal Dysgenesis Sex Dev. 2016;10:147-51.

25. Baetens D, Stoop H, Peelman F, Todeschini AL, Rosseel T, Coppieters F, Veitia RA, et al. NR5A1 is a novel disease gene for $46, \mathrm{XX}$ testicular and ovotesticular disorders of sex development. Genet Med. 2017;19:367-76.

26. Wang $H$, Zhang L, Wang $N$, Zhu H, Han B, Sun F, Yao H, et al. Nextgeneration sequencing reveals genetic landscape in $46, \mathrm{XY}$ disorders 
of sexual development patients with variable phenotypes. Hum Genet. 2018;137:265-77.

27. Chamberlin A, Huether R, Machado AZ, Groden M, Liu HM, Upadhyay $\mathrm{KOV}$, et al. Mutations in MAP3K1 that cause $46, \mathrm{XY}$ disorders of sex development disrupt distinct structural domains in the protein. Hum Mol Genet. 2019;28:1620-8.

28. Murakami S, Kan M, McKeehan WL, de Crombrugghe B. Up-regulation of the chondrogenic Sox9 gene by fibroblast growth factors is mediated by the mitogen-activated protein kinase pathway. Proc Natl Acad Sci USA. 2000;97:1113-8

29. Upadhyay K, Loke JOV, Taragin B, Ostrer H. Biallelic mutations in FLNB cause a skeletal dysplasia with $46, \mathrm{XY}$ gonadal dysgenesis by activating beta-catenin. Clin Genet. 2018:93:412-6.

30. Abreu-Martin MT, Chari A, Palladino AA, Craft NA, Sawyers CL. Mitogenactivated protein kinase kinase kinase 1 activates androgen receptordependent transcription and apoptosis in prostate cancer. Mol Cell Biol. 1999;19:5143-54.

31. Cleutjens KB, van Eekelen CC, van der Korput HA, Brinkmann AO, Trapman J. Two androgen response regions cooperate in steroid hormone regulated activity of the prostate-specific antigen promoter. J Biol Chem. 1996;271:6379-88.

32. Mokhtari D, Myers JW, Welsh N. MAPK kinase kinase-1 is essential for cytokine-induced c-Jun NH2-terminal kinase and nuclear factor-kappaB activation in human pancreatic islet cells. Diabetes. 2008;57:1896-904.

33. Leach DA, Panagopoulos V, Nash C, Bevan C, Thomson AA, Selth LA, Buchanan G. Cell-lineage specificity and role of AP-1 in the prostate fibroblast androgen receptor cistrome. Mol Cell Endocrinol. 2017:439:261-72.

34. Robevska G, van den Bergen JA, Ohnesorg T, Eggers S, Hanna C, Hersmus $R$, Thompson EM, et al. Functional characterization of novel NR5A1 variants reveals multiple complex roles in disorders of sex development. Hum Mutat. 2018:39:124-39.

35. Lu JR, McKinsey TA, Xu H, Wang DZ, Richardson JA, Olson EN. FOG-2, a heart- and brain-enriched cofactor for GATA transcription factors. Mol Cell Biol. 1999;19:4495-502.

36. Tevosian SG, Deconinck AE, Tanaka M, Schinke M, Litovsky SH, Izumo S, Fujiwara Y, et al. FOG-2, a cofactor for GATA transcription factors, is essential for heart morphogenesis and development of coronary vessels from epicardium. Cell. 2000;101:729-39.
37. Bashamboo A, Brauner R, Bignon-Topalovic J, Lortat-Jacob S, Karageorgou V, Lourenco D, Guffanti A, et al. Mutations in the FOG2/ZFPM2 gene are associated with anomalies of human testis determination. Hum Mol Genet. 2014;23:3657-65.

38. Fujimoto Y, Tanaka SS, Yamaguchi YL, Kobayashi H, Kuroki S, Tachibana M, Shinomura M, et al. Homeoproteins Six1 and Six4 regulate male sex determination and mouse gonadal development. Dev Cell. 2013;26:416-30.

39. Kawakami K, Sato S, Ozaki H, Ikeda K. Six family genes-structure and function as transcription factors and their roles in development. BioEssays. 2000;22:616-26.

40. de Santa BP, Moniot B, Poulat F, Berta P. Expression and subcellular localization of SF-1, SOX9, WT1, and AMH proteins during early human testicular development. Dev Dyn. 2000;217:293-8.

41. Avendano A, Paradisi I, Cammarata-Scalisi F, Callea M. 5-alpha-Reductase type 2 deficiency: is there a genotype-phenotype correlation? A review. Hormones (Athens). 2018;17:197-204.

42. Wilson JD, Griffin JE, Russell DW. Steroid 5 alpha-reductase 2 deficiency. Endocr Rev. 1993;14:577-93.

43. Granados A, Alaniz VI, Mohnach L, Barseghyan H, Vilain E, Ostrer H, Quint $\mathrm{EH}$, et al. MAP3K1-related gonadal dysgenesis: Six new cases and review of the literature. Am J Med Genet C Semin Med Genet. 2017;175:253-9.

44. Le Caignec C, Baron S, McElreavey K, Joubert M, Rival JM, Mechinaud F, David A. 46, XY gonadal dysgenesis: evidence for autosomal dominant transmission in a large kindred. Am J Med Genet A. 2003;116a:37-43.

45. Condorelli RA, Cannarella R, Calogero AE, La Vignera S. Evaluation of testicular function in prepubertal children. Endocrine. 2018:62:274-80.

46. Nistal M, Paniagua R, González-Peramato P, Reyes-Múgica M. Perspectives in pediatric pathology, chapter 1. Normal development of testicular structures: from the bipotential gonad to the fetal testis. Pediatr Dev Pathol. 2015:18:88-102.

47. La Vignera S, Cannarella R, Condorelli RA, Calogero AE. Disorders of puberty: endocrinology of the pre-pubertal testis. J Clin Med. 2020;9:780.

\section{Publisher's Note}

Springer Nature remains neutral with regard to jurisdictional claims in published maps and institutional affiliations.
Ready to submit your research? Choose BMC and benefit from:

- fast, convenient online submission

- thorough peer review by experienced researchers in your field

- rapid publication on acceptance

- support for research data, including large and complex data types

- gold Open Access which fosters wider collaboration and increased citations

- maximum visibility for your research: over $100 \mathrm{M}$ website views per year

At BMC, research is always in progress.

Learn more biomedcentral.com/submissions 